\title{
Empowerment of Women Journalists through Technology in Rural Areas of India
}

\author{
Md Afsar ${ }^{1 *}$, Suman Kumari ${ }^{2}$ \\ ${ }^{1}$ Research Scholar, Department of Journalism and Mass Communication, FMeH, MRIIRS, Faridabad \\ ${ }^{2}$ Associate Professor, Department of Journalism and Mass Communication, FMeH, MRIIRS, Faridabad \\ *Corresponding author
}

\begin{abstract}
Indian news media is dominated by male journalists and always present women gender's stereotyping identity in its widespread space. This has culminated to a quest of alternate media platforms that will give larger entree to the media outlets and allow the concerns of marginalized groups to be addressed at their own experiences and terms, specifically women from rural areas. India today presents the rapid rise in the number of Internet users in the world. Women journalists from rural India have started to use independent (based on internet) media effectively to support sustainable development and gender equality in this context. They are reporting and showing their stories not only on electronic and print news media but also on internet (social media and online web based news channels). These medium of communication allow women from rural India to discuss and strengthen their rights over knowledge of various political, social, environmental policies and economic programs. Therefore, aim of this paper is to study and analyze the impact and use of technology by women journalists from rural India. This will enable to further study the engagement of women in upbringing of women taking part in news media world, be in news gathering or news creation and broadcasting. The data is collected via group discussions, interviews, and questionnaires with the women journalists. The study conducted in the paper shows that technology is playing a very significant role in empowering women in rural areas of our country.
\end{abstract}

Keywords: Technology, Women Journalist, Media, Empowerment, Rural

\section{Introduction}

Internet and Mobile Association of India (IAMAI) has conducted a study in which it is mentioned that India's rural mobile internet users have increased by more than ninety percentage since last six years [1]. Technology and Information have become an integral part of primary initiatives to promote women's active participation in several development strategies, particularly for women's growth. Women also started to participate in various news events to promote equality and prosperity among Indians from different regions with different 
backgrounds. Women have also started to play an important role in improving the news content and coverage which deals with the issues faced by women in India [2,3].

In present time, women are equally capable in every sector as men are. Whether we're talking about science, economics, politics, and sports etc., they got more opportunity to participate. Over the years, Internet use for news has grown rapidly in India in recent years, driven in particular by the increase of mobile internet use by the double-digit growth in number of current users.

Presently, news media is evolving as a commercial entity is dictated by a sort of 'benefit interest'. Rural issues are perceived to have a lower profit interest than issues arising from powerful economic centres, and as a result less' media space' is provided in rural areas than the issues which bother urban population [4,5]. Raising rural concerns, whether they relate to atrocities on rural women or living conditions in these areas or their social and economic lives, on media platforms becomes very important [6]. Rural women journalists play a very important role in raising their voices against this inequality in the society $[7,8]$.

In this line, India's first rural newspaper "Khabar Lahariya" was launched in the district of Bundelkhand where 60 percent of the population hangs on agriculture. Their mission was to take rural women into the field of information and technology and journalism. It created a new wave across the bleak landscape, where survival is the subject of life and areas such as education, civil rights and gender equality have taken a backseat. Rural women have also started to use electronic medium such as internet on mobile to disseminate the news relating to the rural women lives $[9,10]$.

Therefore, in this paper, the analysis of technology is done with reference to rural women journalists i.e. how technology has helped them in raising their voices relating to the rural women's social and economic conditions.

The paper is organized in the following sections. Section 2 presents the analysis of the role of technology in the rise of women empowerment of women journalists in the rural areas of our country. Section 3 presents a literature review of the work done by the researchers related to this area. The paper is finally concluded in the Section 4.

\section{Technology and Women Journalist's Empowerment}

In our society, there is a weird trend for women in journalism that women would eventually leave journalism after marriage, or unable to devote time and energy outside their home or that they can only be a beauty symbol even in news media and are not capable of news gathering or broadcasting them. They are then viewed as 'unsound capital' \& tendentiously and therefore, male candidates may be given preference over female journalists. This fact goes more distressingly with the women journalists living in rural areas. However, technology is helping the women journalists to show their talent to a wider space of audiences and ease their job to cover the stories and broadcast them.

Internet has spread exceptionally fast in the urban areas and now is increasingly spreading in the rural areas as well of our country. Rural women are also open and ready to use this 
technology and are being benefitted in many ways. WhatsApp, Facebook, YouTube are being used by rural women journalists to showcase their stories to reach to a wider number of audiences in rural areas.

There is a tremendous growth of the internet and the women living in rural areas used the idea of digitization in the best possible way. Increased use of print and online news platforms by women journalists have encouraged women's liberation, upliftment and shatter their predetermined stereotypical image. Technology is helpful in making an effort to ensure that gender is not considered as a factor in the ability of a journalist and that stories should not be ignored if a woman is the individual who is promoting them.

An official of the project which aims to improvise digital awareness said that this project focuses on imparting knowledge on how to use technology to the women living in rural areas. By learning the internet usage, women will be able to use the technology in order to raise their issues and spread them to get the needed attention of the authorities who will be responsible to resolve them. This will in turn improve their social and economic growth and will increase their participation in welfare of the society. [11]

Now, the use of technology in the rise in women empowerment is highlighted in the following section.

Khabar Lahariya is the initial stone laid in line to empower women in terms of doing jobs for their living and to raise their voices or their rights. It was needed to prove that women too could be reporters despite their lack of training. They specialize in writing interviews and reports and in conducting interviews. Meera, who is Khabar Lahariya's editor-in-chief, says women like her are initially faced with an identity issue [12]. She has faced questions such as: how is she going to tackle the patriarchal feudal system? How is she going to deal with opposition and criticism for her team? Initially, their paper was seen only as a women's paper. However, they wanted to turn it into a rural newspaper that everybody, men and women could read. A woman reporter of Khabar Lahariya Kavita quotes what so many people have said to her, "You are a woman, and how can you do the job of a man?" Also a feminist newspaper, Khabar Lahariya also focuses on stories that concentrate on progress, girls, sexual violence against women, crime, etc. "Reports on dowry, incest, mental trauma, child sexual abuse are written with a sensitivity that few papers can say" [13] .

Since its inception, they have continually expanded and created an online presence in 2013. According to a female reporter, their videos on social media are becoming highly popular among the people living in the rural area. In 2017, they got 1 million monthly page views on their website. One of the female reporter Joshi working with Khabar Lahariya says that before their newspaper become online, its popularity among rural women was very less but as $t$ became online, it increased by quite a high percentage. Now, Khabar Lahariya has dropped its print and has now gone fully digital because of the technology use. They have a million plus viewers on YouTube and have become a regular syndicated news partner for digital English media with $232 \mathrm{~K}+$ YouTube subscribers. They have offline visibility gains traction with editors \& journalists invited for panels, talks, seminars, conferences, both nationally and internationally and induction into Editors' Guild of India [14]. 
Another initiative is "Internet Saathi" launched in 2015 gave knowledge about internet to the women living in rural India in villages of Rajasthan, Jharkhand, and Gujarat. Internet training is provided on smart phones. They trained women who become digital literate to train other rural women in their villages. With this program, over 13.5 million women have benefited in more than one lakh villages in more than ten states of India [15].

Andhra Pradesh state has started a project on rural "elimination of poverty" in small areas of the state. It was launched in which female reporters were trained. At the start, out of 10 mandals in Chittoor district, a group of more than 15 women was chosen to get trained. The Chittoor newsletter covers about 20 mandals. The female journalists were majorly form the backward class and areas of the district of Chittoor. The news stories filed by these female journalists have very attention grabbing event, dances, songs which belong to their culture, living style and conditions. These news stories help the government to make policies in order to improve the living conditions of the women of rural areas [17].

Different women groups, comprising Mahila Samakhya, also publish online periodicals on different growth matters. They publish a Baini publication which aims to cover and spread the news concerned with the rural women [18]. It propagate the matters related to women upbringing and upholds the need for cluster-level training, education societies, crimes against women, data on several government schemes such as Rashtriya Laabh SurakshaYojana, Swarnajayanti Grameen Swarozgar Yojana (SGRY) for widows, Baalika Sammridhi and Matritva Laabh.

Women journalists in Assam's rural areas have covered stories using their smart phone which shows that internet has been used by rural women to change their lives to be in a better economic condition. Bhairabi Devi says that the use of Internet has aided her in terms of discovering new and modern designs by the use of technology. This enables her to follow trend in the ongoing designs for different types of outfits.

Now, the methodology which was used to conduct the research is described below.

$>$ The primary and secondary data both were used to formulate information for our research. Primary sources included a questionnaire used as a pilot study, as well as two telephone interviews conducted with reporters who have been working in the field of journalism. Secondary information sources included internet posts and publications.

$>$ The study for analysis of the women journalists was done in 4 states, Madhya Pradesh, UP, Bihar and Rajasthan. The focus was on understanding the role of technology in women journalist's engagement in state media.

$>$ Data collection comprised of group discussions, interviews, and questionnaires.

$>$ Analysis of the data collected was done to understand how much technology has helped the rural women journalists to empower themselves as well as the common rural women.

Below is the list of sample questions which were used during interviews and questionnaires with the women journalists. 
What device you use while story coverage daily?

$>$ Which online platform you use to broadcast your stories?

$>$ Do you do audio recording or video recording of your stories?

$>$ Do you write story on online platforms like twitter and website?

$>$ Have you taken any training for hands on for the technologies?

$>$ How much comfortable are you in using technology in daily life?

$>$ Have you experienced telephonic abuses or threats to life?

$>$ Have you ever faced mobile phone tapping or email hacking?

$>$ Do you and your stories have any impact after you face any threats?

$>$ How have ever faced online abuse?

Now, the analysis is presented in Figure 1 which is obtained after the completion of data collection for the research. Women journalists were asked questions to analyze the below parameters which helps in understanding how technology has played an important role in empowering the women journalists as well as the rural common women.

1) Knowledge of technology for news coverage

2) Ease in technology usage

3) Ease in news coverage

4) Thorough coverage of stories

5) Enhanced news broadcasting

6) Rural women participation in giving stories

The first parameter is to know that how much women journalists have become aware of the technology over the past years, be it the devices such as mobile phone or tablets etc or the online platforms such as youtube, twitter, facebook etc to disseminate the news. The second parameter is used to study that how many women journalists have become comfortable in using these technologies. The third parameter deals with study of technology usage in news coverage to understand that how technology has become a powerful medium for women journalists to cover news stories over the past 15 years. The fourth parameter helps in understanding that how technology is being used to have a comprehensive coverage of the news by the rural women journalists. The fifth parameter helps us to analyze the role of technology in making the news broadcasting easy and enhanced for the women journalists in rural areas. The last parameter is used to analyze that how many common rural women have been involved in giving the stories in terms of the interviews, stories etc to the women journalists of their areas. 


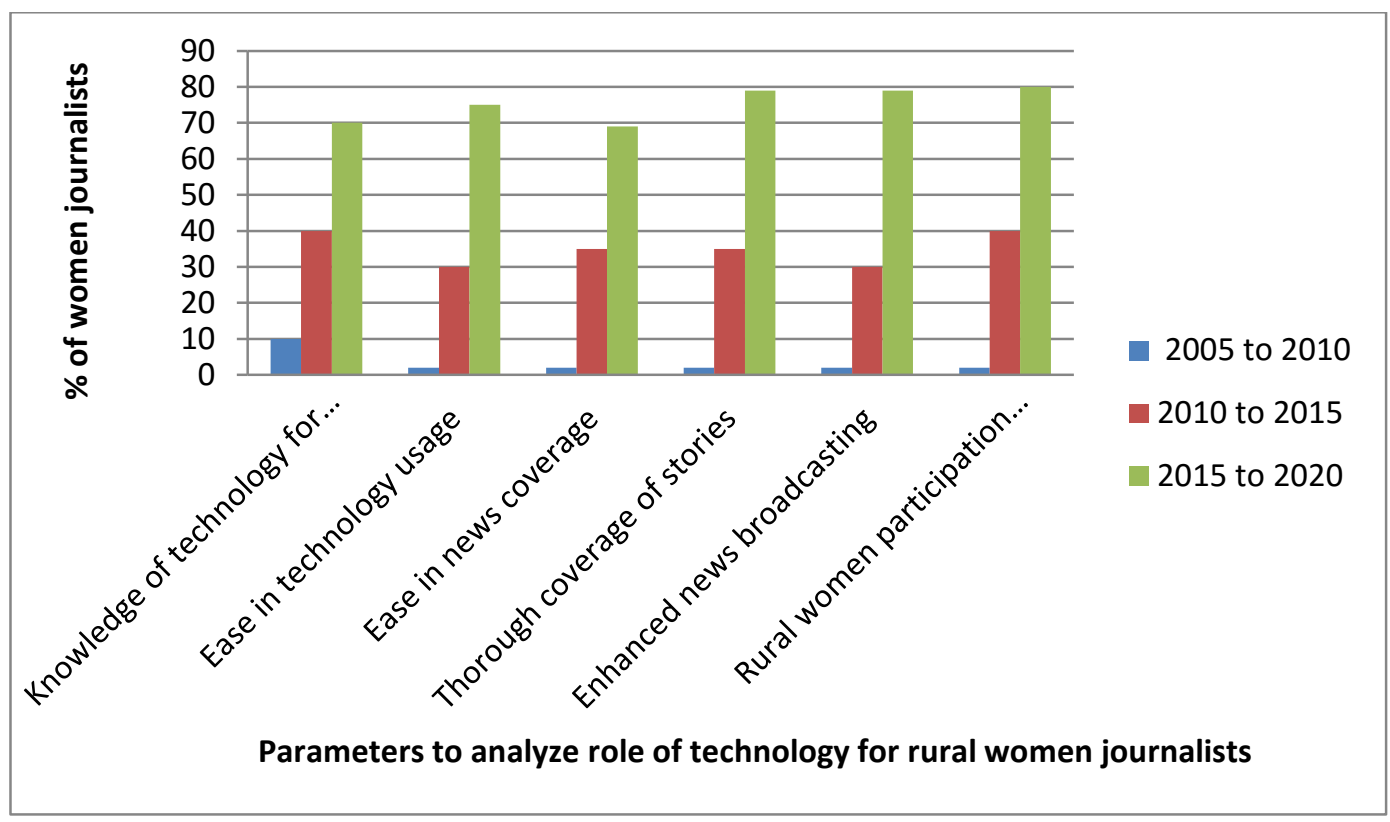

Figure 1: Analysis of role of technology among women journalists over the years

The analysis shows that there has been a significant rise in the percentage of women journalists in rural areas using technology and that the technology has played an important role in women empowerment over the past few years. Also, the study shows that it also helps in the common rural women empowerment.

Women reporters' stories of rural areas require an understanding of India's larger media landscape and how developments have affected the manner in which media is in operation in different parts of the country over the past few decades. This is also a fact that the stringers who are not technically reporters/correspondents are paid less in comparison to the reports and therefore in small and rural areas of India, there is a trend that the news media organization will hire them so that they need to pay less to them. In these areas, they are responsible to maintain their reliability for news which in turn determines their income and distribution of their newspapers. This credibility is being maintained by rural women journalists in a very true and strong manner. Increasing participation of women journalists working in rural areas of India nowadays shows their presence as effective reporters in news media which erodes the thinking that news media can be run by male reporters.

\section{Literature Review}

In this section, we present the research work that has been conducted in the area related to our research.

Shaw discusses the issues faced by female journalists compared to male journalists in' Perceptions of Male and Female Newspaper Journalists in Thailand'. "To the definitions of masculinity, 400 public opinion polls indicated prestige and power. In turn, these conceptions are connected with the beliefs that support the field-i.e., the image of journalism as a male- 
dominated field. "She pins that sex has a role to play in assigning stories in the studies she undertakes [20].

Whether the number of male journalists and the number of female journalists was the same did not matter. For example, female journalists were far less likely to get a story of war. Sangham Radio is a woman-run community radio station. Doordarshan India, posted two articles describing the venture on their website. It stands out because semi-literate dalit women are coordinating. In the positions of editors, program directors, station managers and radio jockeys, the radio station is staffed by all women. This has had an effect on their social status and encouraged them in their personal lives. Close to Khabar Lahariya, this group is all women's organizations.

Research done in [21] study the status of women journalists in Delhi/NCR to analyze how much women reporters are participating in non print news media (TV News channels) and to analyze the way that news channels have adopted HR policies in their organizations. The authors have concluded that the till date also male are working on the designations like news broadcaster, news reader or news producer in major news channels and newspapers whereas the level of involvement of women journalists are not at par with that of male journalists.

Author in [22] presents a study of the disproportionate participation of women and men in the news media and analyse the experience of women journalists while they are at work in their organizations, He says that "Women were included as' women;' that is, as entities whose gender nature prohibits them from having the same political position as men. The political position of women... is packed with paradoxes, inconsistencies and ironies ". This reality illustrates the journalism as a career in which the women participation is not being seen god as for men is seen.

The liberal feminist theory can be extended to the Women in Journalism situation. All people are created equal according to this concept, but women's opportunities are constrained by social constructs and prejudices. Khabar Lahariya provides women with such incentives that they can then smash the standards of society. Females must be free to determine their own social role and be able to compete on an equal footing with men. It is generally thought that the constraints on a woman's life were due to social conditioning and cultural expectations. Through joining male dominated fields and acquiring power positions, they aim to achieve equal status, because men and women are the same. In the case of Khabar Lahariya this can be clearly seen $[24,25]$.

A few of the side effects of mass self-communication tools ' omnipresence is the' sharing' of fake news, misinformation, and misleading social network data, including the WhatsApp mobile messaging service [26]. Media personalities, women leaders, and feminists are some of the other focuses of social media trolling, where there are regular threats of murder, sexual violence and mutilation. The same goes with the women journalists in spite of the fact that they live in urban, semi urban or rural areas in the country.

It can be seen that there is a need to have a study which provides an insight into the emerging role of technology in the empowerment of women journalists in our rural areas. This paper aims to cover this research gap in this area. 


\section{Conclusion}

This paper presented the analysis of role of technology in the rise of women empowerment of rural female reporters. The present era of media is worse, where media is seen as highly commercial, ideological, political, and filthy. However, now the women journalists, be it from rural or urban areas, have become familiar with how to navigate this arena, how to make their place in it and how to question its norms.

The analysis of our research shows that rural women journalists have become more aware and are using the different kinds of digital platform to put them in a position to encounter the rigid stereotypes, both in the personal and social spheres, and put into practice of lived, engaged citizenship. Technology has played an important role in empowering the women from rural areas and is becoming a platform for raising their voices against all kinds of violence, inequalities and injustice done to them.

In the future, the research will be extended to study the life of the women journalist in more depth such as study their social, political and economic lives. Also, work will be extended to study the differences between the perception and the reality of the women journalists in rural areas.

\section{References}

https://economictimes.indiatimes.com/tech/internet/india-to-have-371-mn-mobile-internetusers-by-june-iamai/articleshow/50837732.cms?from $=\mathrm{mdr}$

Bennett, Arnold, 2009, Journalism for women: A practical guide. J. Lane.

Deuze, M. (2005). What is journalism? Professional identity and ideology of journalists reconsidered. Journalism, 6(4), pp: 442-464.

Diwaker, G. "Empowerment and Transformation: A Case Study of Communication Skills of Dalit Women in India." Pan-Commonwealth Forum 7 (PCF7), (2013).

Bhandare Usha V. (2015). Women Exploitation In Media, Volume 4, Issue 2, pp:11-20

Narayana, U. R. (2015). Mainstreaming Women in News-Myth or Reality?.Pragyaan: Journal of Mass Communication, Volume 13, Issue 1, pp: 22-26.

Patowary, H. (2014). Portrayal of Women in Indian Mass Media: An Investigation. Journal of Education \& Social Policy, 1(1). Vol. 1 No. 1. pp:84-92.

Ira N. Gang, KunalSen, and Myeong-Su Yun (2008), Poverty in rural India: caste and tribe. Review of Income and Wealth Journal. pp: 50-70.

Joseph Ammu, Kalpana Sharma, (Eds.), 2006, Whose News? The Media and Women's Issues, Sage. 
Joshi, U., Pahad, A., \& Maniar, A. (2006). Images of Women in Print Media-A Research Inquiry., Indian Media Studies Journal 1.1,pp: 39-51.

https://scroll.in/article/838263/how-the-internet-is-empowering-assams-rural-women

Tomar, Ranu. "Khabar Lahariya: A Feminist Critique of Mainstream Hindi Print Media." About SubVersions.

Thomas, Pradip Ninan. Negotiating communication rights: Case studies from India. SAGE Publications India, 2011.

Ghose, M. A. L. I. N. I., and D. I. S. H. A. Mullick. "Empowerment in educational processes: Feminist re-appropriations." More powerful literacies (2012): 147.

Dhaka, Reena Hooda1\& Deepak. "Internet Saathi in India: How Far We Moved to Drive." Advances in Computational Sciences and Technology 10.5 (2017): 741-746.

Lonsdale, S. 2013, 'We agreed that women were a Nuisance in the office anyway', Journalism Studies.

Prasad, Kiran. "Cracking the glass ceiling: Rural women making news in India." Media Asia 33.3-4 (2006): 229-233.

Kandpal, Eeshani, Kathy Baylis, and Mary Arends-Kuenning. "Empowering women through education and influence: An evaluation of the Indian Mahila Samakhya program." (2012).

Rao, L. (2001) Facets of media and gender studies in India. Feminist Media Studies 1.1. pp: 45-48.

Shaw, Ibrahim Seaga. Business journalism: a critical political economy approach. Routledge, 2015.

Singh N. (2016). Analysing Status of Women Journalists in Indian TV News Channels. Journal of Research in Arts and Education, ISSN 2277-1182.

Roy, S. (2011). Television news and democratic change in India. Media, Culture \& Society, pp: 761-777.

Saltzman, Joe., 2003, "Sob sisters: The image of the female journalists in popular culture." University of Southern California.

The fight within, The Hindu, 14 September, 2017The Better India, http://www.thebetterindia.com/37228/khabar-lahariya-women-journalists/, 2016

Tomar R.(2011), Gender And Media: Status Of Women Journalist In Hindi Print Media In India, EADI General Conference: Rethinking Development in an Age of Scarcity and Uncertainty, United Kingdom

Vaishali, H. B., \& Shivram G. P.. Changing Face of Women Journalists in Leading Kannada Television Channels: A Study. International Journal of Scientific Research 4.8 (2016).

Aggarwal Vir Bala, "Media and Society", Challenges and Opportunities", Concept Publishing Company, 2002 


\section{3rd International Conference on Advanced \\ Research in Social Sciences \& Humanities}

John Allen Hendricks, "The Twenty-First-Century Media Industry: Economic and Managerial Implications in the Age of New Media" ,Marylad: Lexington Books, 2010

Akhilhshvvari R Vidura, "Should Women Opt for Journalism” 27(1), 1990,pp 18-19.

Chakraborty Prithvis, “Outstanding Women journalists” Vidura, 1996 ,33(2), pp. 11- 13.

Bhatnagar, Vinod, "Development Dynamics of Press and journalism" Jaipur. Printwell Publication, 1996

Louis Alvin Day, "Ethics in Media Communications: Cases and Controversies Belmont", CA: Wadsworth. 2003

National Conference on Women and Media. A report, Social Welfare April 2002. 49(1), 120 Natranjan, S.A "history of the press in India" Asia Publishing House, New York 1981. pp. 140-141. Nitz, M., Reichert,

Prasad Kiran (2005). Women and Media: Challenging feminist discourse. The Women Press.

Tomar, Ranu. "Women in Media like ice on cake" .Media Vimarsh, Annual issue, Oct Dec. Bhopal. 2009. pg 74

Toni Bruce "Supportive or Hostile? Teasing or Professional? Women Sportswriters Categorize Locker Room Interaction," Women in Sport and Physical Activity Journal, 2002 11, no. 1 49-61,

"Women welfare and empowerment in India: Vision for 21 st century by Rameshwari Pandya”(20) New Century Publications, 2008 